\title{
Efficacy of Transforming Agriculture for Survival to Commercial Agriculture through 'Kilimo Kwanza' Initiative in Tanzania
}

\author{
Msafiri Y. Mkonda ${ }^{1,2}$, Xinhua $\mathrm{He}^{1,3, \text { * }}$ \\ ${ }^{1}$ Centre of Excellence for Soil Biology, College of Resources and Environment, Southwest University, Chongqing 400716, China \\ ${ }^{2}$ Department of Physical Sciences, Faculty of Science, Sokoine University of Agriculture, Morogoro 3038, Tanzania \\ ${ }^{3}$ School of Plant Biology, University of Western Australia, Crawley 6009, Australia
}

Copyright $\bigcirc 2016$ by authors, all rights reserved. Authors agree that this article remains permanently open access under the terms of the Creative Commons Attribution License 4.0 International License

\begin{abstract}
Kilimo Kwanza which means "Agriculture First" in English, is an initiative launched by the Tanzanian government in 2006 to spearhead the transformation of subsistence to commercial agriculture for curbing poverty. The initiative aimed at solving constrains facing farmers (small, medium and/or large scale). Its implementation is based on ten milestones some of them are the provision of credit to farmers through Tanzania Agricultural Development Bank, good governance, establishment of infrastructure, coordination and evaluation of the milestones. Through "Kilimo Kwanza" for farming credits, the government has pledged 500 million USD to TADB in 2015, though the deal has not made yet. Compared to other initiatives, the special aspect that "Kilimo Kwanza" possesses is that; it is people centered. It works under the patronage of Tanzania National Business Council which involves both private and public dialogue on strategic issues for economic development. Despite of all these efforts and instruments of "Kilimo Kwanza", Tanzanian agriculture has remained the main employer of Tanzanian labour force (70\%), account $24 \%$ of the GDP, $30 \%$ of export and $65 \%$ of raw materials for domestic industry. However, this contribution is insufficient compared to the vision of the initiative. To address the constraints facing Tanzanian agriculture, there is a need to think more widely aiming at arresting all barriers with a clear and committed political will. Among others: motivation/incentives to farmers, extension services, equipping good infrastructures ranging from irrigation, transport and storage facilities. Then, the flow of farm inputs from local government authorities to small and medium scale farmers is a governance issue. The people responsible for the flow of these inputs are not playing their roles despite of the clear directives from the government. Similarly, policies, plans and programmes are well stipulated but, implementation to reach intended outcomes needs further efforts.
\end{abstract}

Keywords Commercial Agriculture, Farmers, Kilimo Kwanza, Poverty Reduction, Tanzania

\section{Introduction}

\subsection{Information Background}

Kilimo Kwanza is a Swahili word means "Agriculture First" in English. It is an initiative launched in 2009 by the former Tanzanian President His Excellency Jakaya M. Kikwete [1]. The major goal of this initiative is to spearhead the growth of Agricultural Sector and transform it to from subsistence to commercial industry [2]. Kilimo Kwanza aims at increasing crop yields to curb food insecurity and poverty in diverse aspects $[3,14,21]$. Before the inception of this initiative, there were other initiatives formed in different times from 1960's to 1990's [23]. Some of the former initiatives which did not make to the end include: Policy is Agriculture, Life and Death Effort to improve agriculture, Arusha Declaration, Villagization, Food is Life, and Modern Agriculture. These initiatives were formed around 1960's to 1990's [21]. However, they did not make to the end because they were centralized with little involvement of the people and private sector. They used top down approach to implement their goals.

Kilimo Kwanza differs from the former initiatives in several ways [23]. It has showed up some improvements in terms of approaches and magnitude of stakeholder's involvements [18]. It involve private sector which is the engine for economic development with enormous magnitude to national development. As well, it is a holistic approach aiming to address numerous challenges facing agricultural sector

Kilimo Kwanza is the central pillar to achieve the 
Tanzania Vision 2025 which aims to make the country a middle income country by the year 2025 [18, 23]. It was formulated under the patronage of Tanzania National Business Council; a forum for economic development in Tanzania. This involves both private and public sectors [18].

\subsection{Rationale of Kilimo Kwanza}

Kilimo Kwanza was mainly established to accelerate economic development in the county [14,24]. It aims to curb food insecurity and poverty to small, medium and/or large scale farmers. Tanzania agricultural sector is a good engine for socio-economic development of the country [25]. The development of the sector meant to develop over $80 \%$ of the people $[24,25]$.

Tanzanian agriculture employs over $70 \%$ of the labourforce, it account $24 \%$ of the Gross Domestic Product, $30 \%$ of the total export and $65 \%$ of the raw materials consumed in domestic industries [3,4,5]. Moreover, it provide strong economic link with other non-farm sectors $[18,19,20]$. On top of that, agriculture helps to control economic inflation as food contribute to about $50 \%$ of the inflation basket $[18,20,25]$. Thus, the development of agricultural sector has a strong economic link to other sectors and entire livelihoods of the people especially in rural areas.

Kilimo Kwanza aimed to speed up the utilization of potential available for agriculture. Tanzania has about 44 million hectares of arable land but less than 24 of this land is harnessed. Apart from arable land, the country has millions of animals ranging from cattle (19milion), Sheep (17milion) and Chicken (30million) which are not well commercially exploited.

Therefore, Kilimo Kwanza also aims to speed up the implementation of some agricultural related programs from local to national level $[6,7,8]$. The Agricultural Sector Development Program is a good example of these programs $[9,10]$. It is implemented at district level to fasten the development of agriculture sector and is implemented through Public Private Partnership (PPP).

Despite the aims of Kilimo Kwanza being good, we have reviewed its functions and come up with some evaluations and resolutions.

\subsection{Agricultural Status Since 1960's to 2005}

The trend of crop production especially cereal crops has been fluctuating over time. Impact of climate change, level of investment and attitude towards agriculture are among the factors for this fluctuation $[11,12,13]$. Early 1960's maize production increased because of the market value. In those years the price of food crop in the World Market increased suddenly, responding to the increased demand. Therefore, Tanzania increased the production of food crops $[19,20]$. However, in 1970's, Tanzania faced severe famine caused of crop failure. This was caused by drought occurred in the years $1973 / 1974[14,15,16]$. It was during these years (1970's) when some initiatives were launched to instill the production spirit of food crops. Life and Death Effort to improve agriculture, Villagization and Food is Life were among the initiatives formed in those years $[18,19]$.

Thereafter, in 1980's fluctuation trends continued and the Structural Adjustment Program was adopted to increase the production in each economic sector. However, the centralization and top down approach hindered its sustainability [19]. In 2000's the use of decentralization approach increased the production of crop to some extent [18]. A number of agricultural program and project funded by both foreign and domestic donors have been operating to increase crop yields. It was during that time when Kilimo Kwanza initiative was launched.

The failure of cereal crops has been bringing problem because they are staple food for the majority Tanzanians $[10$, $20,21]$. However, the production of cereal crops is determined by climate and soil requirements of the area or geographical biome [11, 12].

Tanzania has 7 main agro-ecological zones and about 30\% of the country area $\left(945087 \mathrm{~km}^{2}\right)$ is a semi-arid. This is the most vulnerable area to the impacts of climate change and abject poverty [13]. Drought resistant crops are encouraged to be grown in this area. According to Rowhani et al. (2011) rainfall variability has been reducing crop yields where it has reduced 4.2\% (maize), 7.2\% (sorghum), and 7.6\% (rice), Subsequently, it is projected that by 2050 climate variability will effect on crop yields in Tanzania by $3.6 \%, 8.9 \%$, and $28.6 \%$ for maize, sorghum and rice respectively $[1,17]$.

The production trend of cereal crops from 1961 to 2010 shows the level of fluctuation with respect to population growth (Fig. 1). We have viewed the three aspects i.e. population, area under cultivation and the food crops yields to determine their ratio. This is because crops yields may increase due to over expansion of farm land and not improvement per hectare. Similarly, the yields may increase but with less extent than population does. If these conditions happen, we cannot make inference that crops yields have increased and curbed food insecurity. This condition can be referred to Malthusian theory which observed that food was increasing arithmetically while population was growing geometrically.

\section{Profile of the Study Area}

\subsection{Location and Methodology}

Tanzania is located in the eastern part of Africa between longitude 290 and 410 east and latitude 10 and 120 south. It borders the Indian Ocean to the east, Uganda and Kenya to the north, Burundi, Rwanda and the Democratic Republic of Congo to the west, and Mozambique, Zambia and Malawi to the south. Its total land area is $945087 \mathrm{~km}^{2}$. Agricultural land accounts for about 40.1 percent of the total land area [19]. An estimated 55 percent of the land in the United Republic of Tanzania could be used for agriculture, and more than 51 
percent for pasture. However, only about 23 percent of the agricultural land is cultivated, and the practice of shifting cultivation causes deforestation and land degradation on pastoral land [20]. Figure 2 below show the spatial cereal production in Tanzania. There is direct proportion between the level of cereal production and agro-ecological zones.

Methodology: We reviewed 26 publications all from authentic sources. Papers published in international journals, government report and publications by international organizations were given high consideration in the vetting. It is obvious that the results from this sort of screening are authentic and representative. In addition, the authors of this paper shared their opinions on the reviewed data. Their views were shared during discussion under each section.

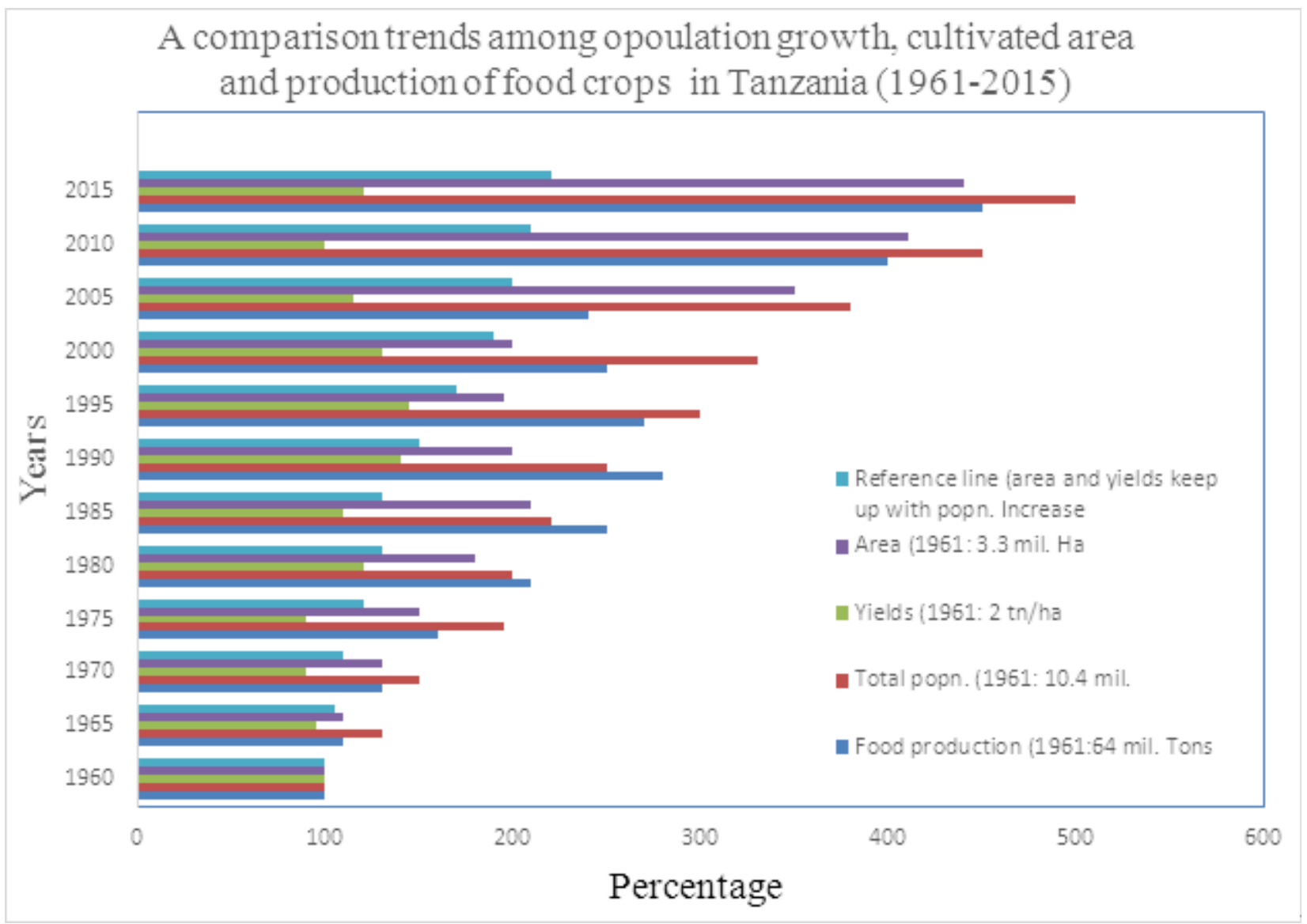

Source: Modified from Leliveld [9]

Figure 1. Population and agricultural trends Tanzania 1961-2010 (Index year 1961=100) 
Tanzania: production ( $m t$ cereal eq/cap)

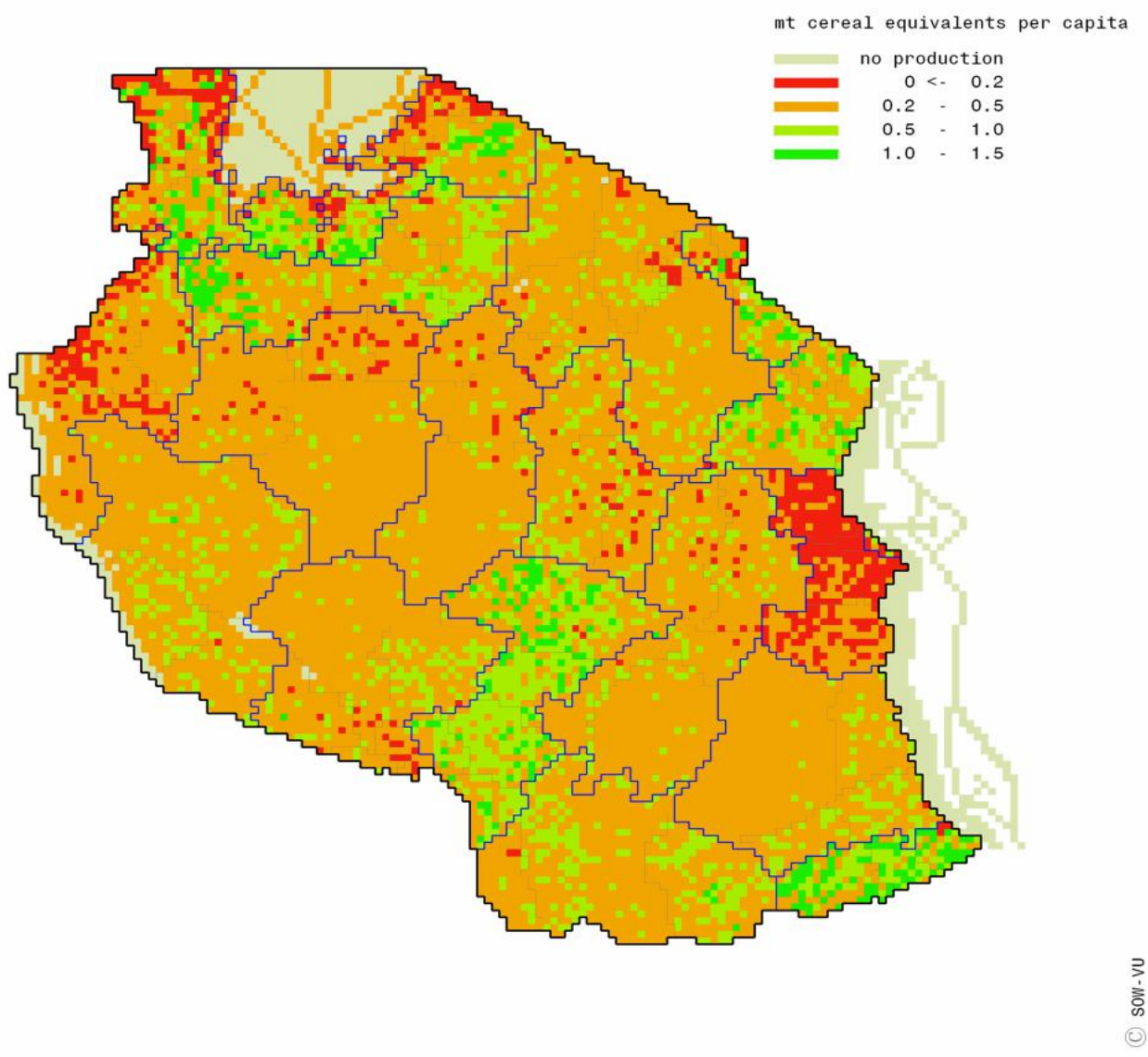

Source: Adopted from Leliveld [9]

Figure 2. Major agricultural production areas in Tanzania, around 2005 to date

\subsection{Climate}

Tanzanian climate is influenced by its location close to the equator, the impact of the Indian Ocean and the physiography in general. As a consequence, Tanzania experiences a variety of climatic conditions ranging from humid coastal to alpine deserts crowning the high peaks of Kilimanjaro and Meru mountains to highland montane forest and moist tropical forest. The coastal area and all of the islands in the Indian Ocean experience a tropical climate, and most of the country is sub-tropical except for the areas at higher altitudes. Wet season rainfall averages 50 to $200 \mathrm{~mm}$ per month, but differs among regions and reaches about 300 mm per month in the wettest parts [20, 21, 23, 24].

\subsubsection{Temperature Pattern}

Average temperatures range between $17^{\circ} \mathrm{C}$ and $27^{\circ} \mathrm{C}$, depending on location. The hottest period spreads between November and February $\left(25^{\circ} \mathrm{C}-31^{\circ} \mathrm{C}\right)$ while the coldest period occurs between May and August $\left(15^{\circ} \mathrm{C}-20^{\circ} \mathrm{C}\right)$. However, in the mountainous areas and Plateaus, the temperature occasionally drops below $15^{\circ} \mathrm{C}$ at night during the months of June and July. In the Southern highlands temperature can even reach as low as $0^{\circ} \mathrm{C}-6^{\circ} \mathrm{C}$. Temperature variations have significant impact on the agro-ecological zones and the adaptation strategies in the agriculture sector.

\subsubsection{Rainfall Pattern}

Rainfall in about $75 \%$ of the country is erratic and only $21 \%$ of the country can expect an annual rainfall of more than $750 \mathrm{~mm}$ with a $90 \%$ probability. As a result, crop and livestock production under such conditions remain vulnerable to the vagaries of the weather. The mean annual rainfall varies considerably from place tom place ranging from less than $400 \mathrm{~mm}$ to over $2,500 \mathrm{~mm}$ per annum. Two rainfall regimes exist over Tanzania. One is unimodal (start as early as mid-November in some places and end as late as mid-May) and the other is bimodal (October -December and March - May). The former is experienced in southern, south-west, central and western parts of the country, and the latter is found to the north and northern coast. In the bimodal regime the March - May rains are referred to as the long rains or "Masika", whereas the October - December rains are generally known as short rains or "Vuli" [13, 14, 26].

\section{Policies, Programs and Initiatives Guiding Agricultural Sector}

Tanzanian Agricultural Policy of 1997 is the driving 
engine of Tanzanian agriculture. It is ambitious to develop agriculture in the country [21]. The policy recognizes the environment with is components i.e. land, water, forest and air as significant and determinant factor for agricultural production. The major theme of the policy is to secure food security and reduce poverty in the country through increased food crops and livestock product [21].

Some of the instruments used to implement the policy include; (i) research, extension and evaluation (ii) monitoring and evaluation of agricultural development (iii) collection and dissemination of market information (iv) provide good infrastructure such as storage, transport and irrigation facilities. Despite of all the above objective and instruments; the policy has not yet exhausted the demand. The after, programs, plans and projects have been introduced and implemented to spearhead the development of the sector. Agricultural Sector Development Program is implemented at district level to fasten and increase food production. This is an approach of decentralization which defines the needs from local level [23].

\section{Adoption of Kilimo Kwanza Initiative}

Kilimo Kwanza was adopted and made into use since 2009 after being launched by the President. At the beginning the level of adoption was good because it involved government support in terms of cash. The importation and use of power tillers tractor was theoretically acceptable. However, it came into problems because majority of farmers are poor and they are using hand hoe $[21,22]$. They could not afford the price of those farm implements. As well, the tendering of importing power tillers involved into a scam of corruption and therefore the situation threatened its sustainability $[18,19,20]$. With collaboration with other sector like ministries for infrastructures, finance, water and division of environment; the government tried at its best to create awareness and enthusiasm to people so as to adopt Kilimo Kwanza initiative. Despite of all those strategies and resources; the projects under Kilimo Kwanza are temporal and therefore the sustainability of the initiative is at stake.

\section{Implementation of Kilimo Kwanza}

Kilimo Kwanza initiative plays great role as a central pillar to the Tanzania Vision 2015. Its implementation is based on ten pillars which aim to curb the challenges facing Tanzanian agriculture. The ten pillars include:

\subsection{Kilimo Kwanza Resolutions}

This is the first pillar of Kilimo Kwanza. It involves the creation of awareness and enthusiasm towards the adoption of the initiative. It instills the political will and commitment to all Tanzanians. The major theme is transformation of subsistence to commercial agriculture $[18,23]$. The major groups involve small, medium and /or large scale farmers [18]. All these intend to raise acceptance and adoption of the initiative. However, there is a wide gap between theory and implementation.

\subsection{Financing Kilimo Kwanza}

Finance is a major problem facing different sectors including agriculture [24]. To curb the challenge, Kilimo Kwanza emphasizes diverse financial institutions to provide credits to farmers for agricultural production. Apart from financial institution; financing Kilimo Kwanza was expanded to government, development partners, non-governmental organizations and community based organization [25]. The Tanzania Agricultural Development Bank was established as a major component to finance agriculture. The banks are set to provide credits to small, medium and/or large scale farming [23]. The establishment of agricultural banks is a common custom to developed countries which has reached maximum level of level of food security. A good example is China which has China Agricultural Banks among other things the bank finances agriculture. However, a large proportional of land is not formalized and therefore farmers cannot use it as collaterals.

\subsection{Institutional Re-organization for Managing Kilimo Kwanza}

The smooth function and implementation of activities needs a good managing platform. Clear and coherent management systems of Kilimo Kwanza is built on good governance i.e. transparency, accountability and good decision making. Transparency operates under the auspice of good coordination among the instruments involved, good monitoring and evaluation based on the objective of the initiative [23]. Thus, there is a clear bond between private and public sectors. However, barriers like corruption in public sectors, bureaucracy and incompetency seem to ruin the essence of good governance [21].

\subsection{Paradigm Shift to Strategic Framework of Kilimo Kwanza}

Evaluation of production priorities is done in this phase. Priority is done to what people produce and market. Prioritization is done to enlist what crops should be produced by the people [18]. The base of prioritization is on the crops that provide food and market [19]. "Produce what we consume and consume what we produce". However, traditional crops which used to be produced for a long time are usually given more priorities.

\subsection{Land Resources}

Tanzania is having about 44 million hectares of arable land potential for agriculture. Despite of this potentiality; less than $24 \%$ of this potential is harnessed. This happen while a 
big portion of the people have food insecurity [18]. Therefore, Kilimo Kwanza initiative aimed at effective utilization of land resource to increase crop yield and curb poverty [21, 22]. Since the development of land resources need financial capital; the initiative aimed at land formalization to enable the farmers to use their land as collateral when seeking credits to financial institution [23]. However, formalization of land resources is not yet fulfilled. Less than $20 \%$ of the land is formalized.

\subsection{Incentive for Kilimo Kwanza}

This involves motivation of farmers to invest in agriculture. There are some incentives put forwards to motivate farmers [8]. In this aspect the initiative reviews the incentive policy and regulations to attract investment in the sector [7]. This incentive applies both to local and foreign investors. However, the sector has not yet made to sincerely encourage full investment in agriculture [9]. That is why some people use land as collateral to loan money to diverse financial institution but yet they use this money to invest in other sectors such as building hotels and selling industrial goods [23]. They do not invest in agriculture because they make some trade-off and realize that agriculture sector has more investment risk compared to other sectors.

\subsection{Industrialization of Kilimo Kwanza}

Industrialization is a benchmark of commercial agriculture [22]. For sustainable commercialization of agriculture; industrialization plays a great role of adding values to agricultural product before export. Exportation of unfinished agricultural products subject farmers to great economic loss [23].

Therefore, industrialization of agricultural product aims at adding economic values to goods compared than exporting raw materials. However, this has also not yet made because the country is struggling to invest in industries but with poor or little success [25]. Investors as well may not prefer to invest in industries processing agricultural product instead they opt to invest in more paying sectors.

\subsection{Science, Technology and Human Resources}

The application of advanced technology in agriculture is also well considered in Kilimo Kwanza initiative. These involve the use of advanced farm implements, strengthening of research institutes and improve extension services [24]. To implement these aspects, the agricultural yearly budget needs to consume up to $10 \%$ of the total budget.

Tanzania has a number of agricultural institutions ranging from university to college. Sokoine University of Agriculture is leading upon this. Good refereed papers and international conference are made [21]. However, little improvement has been made because the main stakeholders who are peasants have no access to this knowledge. Experts have kept on presenting knowledge among them and therefore, preaching to the converted. There is no umbilical cord connecting between local farmers and researchers.

\subsection{Infrastructure Development}

Tanzania as other Sub-Saharan countries is subject to poor infrastructures especially in rural areas. In this aspect, infrastructure includes roads, irrigation facilities and storage facilities to mention few [22]. Kilimo Kwanza initiative discovered this challenge and started to address some of them. Irrigation scheme in flood plains like Kilombero, Usangu and Ruvu plains to mention few have been improved [24]. Transport network especially roads have been linked but with incomplete transport index. They do not link all areas especially in rural areas which are production zones. Even irrigation and storage facilities are not well accorded to meet the demands [25].

During 2013/2014 season, the major six maize producing regions i.e. Iringa, Mbeya, Ruvuma, Rukwa, Morogoro and Kigoma produced surplus foods. Some of this food was destroyed by rainfall because they were not well stored. They were haphazardly pilled near the farmers' houses.

\subsection{Mobilization of Tanzanians}

For sustainable implementation of the initiative; mobilization, creation of awareness and enthusiasm were determined by Kilimo Kwanza initiative [20,23]. Sensitization on the potential benefits from the initiative was made towards farmers. This meant to get support because farmers are the main target of the initiative $[19,20]$. However, little impact has been made on this because some farmers regards that there were even good agricultural initiative than Kilimo Kwanza but they ended up with little or no success at all. Thus, some regards Kilimo Kwanza as business as usual.

\section{Situation after Kilimo Kwanza}

Recent situation of food crop production shows that we are still experiencing regular food shortage despite of the increase in crop yields in diverse areas. There are spatial and temporal variations in cereal crop production. In region like Iringa, Mbeya, Ruvuma, Rukwa, Morogoro and Kigoma; production levels of food security has been high. However assurance of food security may be subject to other factors.

Since $2000 / 2001$ to $2013 / 2014$ the country has been facing a great fluctuation of crops yield of the major food crops [18]. These crops include maize, rice, sorghum, millet, beans and cassava to mention few. And, it is these crops which determine food security in the country because they are staple food about to all Tanzanians. Food requirement for food crops in 2013/2014 was 7, 656, 673 tons but the amount produced was $7,613,221$ tons $[1,17,18]$. There was a deficit of 43, 452 tons. Despite of other human factors; the impacts of climate change; and degraded and nutrient-poor soils 
played a great role in this food deficit $[7,14,15,16,26]$. In terms of location; there is spatial variation of crop yields of the major food crops produced in Tanzania.

For example; Iringa, Mbeya, Rukwa Ruvuma, Morogoro and Kigoma are regions which always attain the self-sufficient ratio over $100 \%$ thus having food security whilst the majority of the remaining regions have food deficit as they have sufficient ratio under 100\% [18]. Food shortage is more pronounced in Singida, Dodoma, Shinyanga and Mwanza regions which experiences the semi-arid climate and therefore is vulnerable to impacts of climate change [18]. Therefore, the status agriculture in the country with respect to transformation to commercial agriculture is still weak despite of supporting the livelihoods of over $70 \%$ of the Tanzanians.

\section{Challenges Facing Kilimo Kwanza and Agricultural Sector in Tanzania}

Tanzanian agriculture is subject to a wide range of problems. These range from human to natural factors. Despite of intending to address the problems as presented in its pillars; Kilimo Kwanza has not arrested the problems facing the sector [10]. The ten pillars try to exemplify the problems to be addressed by the initiative. However, about all the problems intended to be solved still exist.

This happens because some are solved partially while others are coming as new challenges. Shortage of capital is still an alarming problem despite of the establishment of Tanzania Agricultural Development Bank to give credits to farmers $[18,23]$. Poor infrastructures, poor technology and lack of incentives are still the barriers to undertake agriculture. It is these reasons which deny the exploitation of 44 million hectors of arable land across the country.

\section{Emergence of Big Results Now Initiative}

Big Result Now (BRN) is an initiative adopted to spearhead the development of economic sector with focus on i) Energy and natural gas ii) Agriculture iii) Water iv) Education v) Transport and vi) Mobilization of resources. It was formed as a continuation of Kilimo Kwanza initiative with expansion of economic sectors to be looked upon [18].

Big Result Now is a Malaysian model adopted to facilitate quick development. Tanzania adopted it as a continuation of the Kilimo Kwanza initiative. Results Now (BRN) initiative aims at adopting new methods and approaches of working under specified timeframe for delivery of the step-change required. It needs to speed ups economic development by looking some other sectors beside agriculture in order to fasten achievement of Tanzania Vision 2025 [23].
The vision 2025 aims to place Tanzania a middle income country by 2025 . However, multiple challenges act as barrier to achive this vision. During independency in 1961, it was prospected that Tanzania will be the developed nation by $2020[18,23]$. About 9 years remains to reach 2025 but we are still struggling to make the vision possible. However, according to the existing situation it is very rare to make the expectations true.

\section{Conclusions and Recommendations}

Based on the review, we have reached the following conclusion; Kilimo Kwanza helped to speed up the development of agriculture sector for some years. It increased food security at national level despite the weaknesses emerged at local level. However, the challenges intended to be addressed are mainly still existing or are potentially emerging one again [1-10].

We recommend that; for the initiative to give the needed results there should be strong economic base and good monitoring of the available resources. Economic base will facilitate the achievement of the intended goals. For this initiative to be sustainable, strong political will need to be adhered so that the government can full implement all KK allied programmes $[8,9,23]$. In whole, we need to undertake several studies on agricultural policy and allied programmes that will be helpful to the government in shaping and improving agricultural sector in the country.

\section{Acknowledgements}

The authors give thanks to the authors of the journal papers, books and reports from which he has reviewed his work. In addition, they are indebted to two anonymous reviewers for their constructive criticisms, comments and insights.

\section{REFERENCES}

[1] S. Ahmed, N. Deffenbaugh, T. Hertel, D. Lobell, N. Ramankutty, A. Rios, P. Rowhani, Climate volatility and poverty vulnerability in Tanzania. Global Environmental Change, (2011).

[2] G. Branca, L. Lipper, N. McCarthy, M. Jolejole, Food security, climate change, and sustainable land management. Agron. Sustain. Dev. Vol. 33, (2013), 635-650

[3] FAO, Climate-smart agriculture sourcebook. FAO, Rome, (2014).

[4] IPCC, Climate Change 2014 Impacts, Adaptation, and Vulnerability. Part A: Global and Sectoral Aspects. Contribution of Working Group II to the Fifth Assessment Report of the Intergovernmental Panel on Climate Change [Field, C.B., V.R. Barros, Estrada, R.C. Genova, B. Girma, 
E.S. Kissel, A.N. Levy, S. MacCracken, P.R. Mastrandrea, and L.L. White (eds.)]. Cambridge University Press, Cambridge, United Cambridge, United Kingdom and New York, NY, USA, (2014a).

[5] IPCC, Climate Change 2014: Impacts, Adaptation, and Vulnerability. Part B: Regional Aspects. Contribution of Working Group II to the Fifth Assessment Report of the Intergovernmental Panel on Climate Change [Barros, V.R., C.B. Field, D.J. Dokken M.D. Mastrandrea, K.J. Mach, T.E. Bilir, M. Chatterjee, K.L. Ebi, Y.O. Estrada, R.C Genova, B. Girma, E.S. Kissel, A.N. Levy, S. MacCracken, P.R. Mastrandrea, and L.L White (eds.)]. Cambridge University Press, Cambridge, United Kingdom and New York, NY, USA, (2014b).

[6] A. Kalhapure, B. Shete M. Dhonde, Integrated Nutrient Management in Maize (Zea Mays L.) for Increasing Production with Sustainability. International Journal of Agriculture and Food Science Technology. ISSN 2249-3050, Volume 4, Number 3, (2013), pp. 195-206

[7] A. Kimaro. M. Mpanda, J. Rioux, E. Aynekulu, S. Shaba, M. Thiong'o, P. Mutuo, S. Abwanda, K. Shepherd, H. Neufeldt, S. Rosenstock, Is conservation agriculture 'climate-smart' for maize farmers in the highlands of Tanzania? Springer-Verlag Berlin Heidelberg, (2015).

[8] C. Kucharik, S. Serbin, Impacts of recent climate change on Wisconsin corn and soybean yield trends. Environ. Res. Lett. 3, (2008).

[9] A. Leliveld, T. Dietz, W. Klaver, B. Kilama, D. Foeken Research Report 2013-ASC-3. Agricultural dynamics and food security trends in Tanzania. London/Leiden (2013).

[10] D.B. Lobell, M.B. Burke, Why are agricultural impacts of climate change so uncertain? The importance of temperature relative to precipitation. Environ. Res. Lett. (2008).

[11] J. McGuire, L. Morton, A. Cast., Reconstructing the good farmer identity: shifts in farmer identities and farm management practices to improve water quality. Agric Hum Values, Vol. 30, (2013) pp 57-69.

[12] F. Meijboom, F. Stafleu, Farming ethics in practice: from freedom to professional moral autonomy for farmers. Agric Hum Values, (2015).

[13] M. Y. Mkonda, Impacts of climate change and variability on crop production and its implications to food security a case of Mvomero District, Tanzania. Master's dissertation,
University of Dar-Es-Salaam, (2011).

[14] H. Mongi, A. E. Majule, J. G. Lyimo, "Vulnerability Assessment of Rain-fed Agriculture to Climate Change and Variability in Semi-arid areas of Tanzania" African Journal of Environmental Science and Technology, Vol. 4(6), (2010), 370-383.

[15] J. Mtengeti, F. Brentrup, E. Mtengeti, L. O. Eik, R. Chambuya, Sustainable Intensification of Maize and Rice in Smallholder Farming Systems Under Climate Change in Tanzania, (2014).

[16] J. Paavola, Livelihoods, vulnerability and adaptation to climate change in Morogoro, Tanzania. Environ Sci Policy, (2008).

[17] P. Rowhani, D. B. Lobell, M. Linderman, N. Ramankutty, (Climate variability and crop production in Tanzania. Agric For Meteorol, (2011).

[18] URT, Review of food and agricultural policies in the United Republic of Tanzania. MAFAP Country Report Series, FAO, Rome, Italy, (2014).

[19] URT., Millennium Development Goals report: Midway evaluation 2000-2008.Dar es Salaam, (2008).

[20] URT., Review of food and agricultural policies in the United Republic of Tanzania. MAFAP Country Report Series, FAO, Rome, Italy (2013).

[21] URT, Agriculture and Livestock Policy of Tanzania (1997).

[22] URT, National Strategy for Growth and Reduction of Poverty II (NSGRP II). Dar es Salaam, Ministry of Finance and Economic Affairs, (2010b).

[23] URT, ASDP Performance Report 2009/10. Dar es Salaam, (2011a).

[24] URT, Tanzania Agriculture and Food Security Investment Plan (TAFSIP). Dar es Salaam, (2011b).

[25] URT, Economic Survey 2009. Dar es Salaam, Ministry of Finance and Economic Affairs, (2010a).

[26] P. Yanda, E. Kalumanga, P. Mubaya, "Post Dialogue Report" Integrating Climate Change Adaptation and Mitigation in Development Planning: National Science-Policy Dialogue in Tanzania. Workshop Held on January $20^{\text {th }}$ to $22^{\text {nd }} 2010$, Kunduchi Beach Hotel, Dar es Salaam. Tanzania, (2010). 